\title{
Shared and non-shared antigens from three different extracts of the metacestode of Echinococcus granulosus
}

\author{
David Carmena/ ${ }^{++}$, Jorge Martínez, Aitziber Benito, Jorge A Guisantes/ ${ }^{+}$
}

\author{
Departamento de Inmunología, Microbiología y Parasitología, Facultad de Farmacia, Universidad del País Vasco, Apartado 450, \\ 01080-Vitoria, España
}

\begin{abstract}
Hydatid cyst fluid (HCF), somatic antigens ( $S$-Ag) and excretory-secretory products (ES-Ag) of Echinococcus granulosus protoscoleces are used as the main antigenic sources for immunodiagnosis of human and dog echinococcosis. In order to determine their non-shared as well as their shared antigenic components, these extracts were studied by ELISA-inhibition and immunoblot-inhibition. Assays were carried out using homologous rabbit polyclonal antisera, human sera from individuals with surgically confirmed hydatidosis, and sera from dogs naturally infected with E. granulosus. High levels of cross-reactivity were observed for all antigenic extracts, but especially for ES-Ag and S-Ag. Canine antibodies evidenced lesser avidity for their specific antigens than antibodies from human origin. The major antigenic components shared by HCF, S-Ag, and ES-Ag have apparent molecular masses of 4-6, 20-24, 52, 80, and 100-104 kDa, including doublets of 41/45, 54/57, and 65/68 kDa. Non-shared polypeptides of each antigenic extract of E. granulosus were identified, having apparent masses of 108 and 78 $\mathrm{kDa}$ for HCF, of 124, 94, 83, and $75 \mathrm{kDa}$ for $S$-Ag, and of 89, 66, 42, 39, 37, and $35 \mathrm{kDa}$ for $E S-A g$.
\end{abstract}

Key words: Echinococcus granulosus - hydatid cyst fluid - somatic antigens - excretory-secretory antigens - cross-reactivity

Echinococcosis caused by cestodes of the genus Echinococcus is one of the major zoonotic helminthiosis, causing considerable socio-economic consequences in endemic areas. Due to its world-wide distribution and its important impact in both human and animal health, $E$. granulosus is considered the most relevant species (Romig 2003). The adult worm lives in the small intestine of dogs and other canids, in intimate contact with the intestinal epithelium. The intermediate larval stage (metacestode) can grow in a wide range of mammal species including humans, that acquire infection through accidental ingestion of eggs. Currently, diagnosis of hydatidosis/echinococcosis is based on a combination of imaging techniques (ultrasonography, computerized axial tomography, X-rays) and immunodiagnostic methods such as ELISA and immunoblotting (Zhang et al. 2003).

For immunodiagnosis of human hydatidosis and dog echinococcosis, hydatid cyst fluid (HCF), somatic antigens (S-Ag) and excretory-secretory products (ES-Ag) of E. granulosus protoscoleces and adult worms are used as main antigenic sources. The choice of the most appropriate antigenic extract depends on the developmental stage of the worm and the host species. Thus, HCF is mainly used for the immunodiagnosis of human cystic echinococcosis, based on the detection of antigen 5 and

Financial support: FIS, Ministry of Public Health and DEMSAC, Town Council of Vitoria, Department of Public Health, Basque Government, Spain

${ }^{+}$Corresponding author. E-mail: oipgudej@vc.ehu.es

${ }^{++}$Present address: MRC Clinical Sciences Centre, Membrane Transport Biology Group, Hammersmith Hospital Campus, Du Cane Road, London W12 0NN, UK

Received 2 August 2005

Accepted 23 November 2005 antigen $\mathrm{B}$. The subunit of $8 / 12 \mathrm{kDa}$ from antigen $\mathrm{B}$ is considered the most specific component of $\mathrm{HCF}$ in the genus Echinococcus (Verastegui et al. 1992, Zhang et al. 2003). $\mathrm{S}-\mathrm{Ag}$ from protoscoleces have been used for the serodiagnosis of dog echinococcosis, as protoscoleces are the infective stage of the parasite in the definitive host. However, because of their variable diagnostic sensitivity and high cross-reactivity levels with antigens from other parasite species, S-Ag are unreliable for serodiagnostic purposes (Gasser et al. 1988, 1994, Jenkins et al. 1990, Lightowlers \& Gottstein 1995). In the last few years, ES$\mathrm{Ag}$ from protoscoleces has become the main antigenic source for the immunodiagnosis of dog echinococcosis, based on the detection of parasite antigens in fecal samples (coproantigens) by ELISA (Jenkins et al. 2000, Benito \& Carmena 2005).

Currently, there is very little information available about the recognition of antigenic components from different extracts of E. granulosus by sera from infected individuals of diverse species (Auer et al. 1988, Gasser et al. 1992). In this paper we present a comparative analysis of the cross-reactive antigenic components of $\mathrm{HCF}, \mathrm{S}-\mathrm{Ag}$, and ES-Ag from protoscoleces of E. granulosus by ELISAinhibition and immunoblot-inhibition assays, in order to determine the non-shared and shared antigenic components of these extracts. These data may provide valuable information for the identification and isolation of specific antigenic components from the metacestode of $E$. granulosus for immunodiagnostic purposes.

\section{MATERIALS AND METHODS}

$H C F$ - HCF was obtained from liver and lung fertile cysts of ovine origin as described by Varela-Díaz et al. (1974). Briefly, HCF was centrifuged at $2000 \times \mathrm{g}$ for $45 \mathrm{~min}$, then passed through a Millipore AP20 filter (Bedford, US) and dialyzed against distilled water, using dialysis tubing with a cut-off of $5 \mathrm{kDa}$ (Medicell, London, UK). Finally, 
$\mathrm{HCF}$ was centrifuged at $6500 \times \mathrm{g}$ for $30 \mathrm{~min}$, lyophilized and stored at $4^{\circ} \mathrm{C}$. To perform this study a pool of hydatid fluid from several large cysts from a single sheep lung was used. The concentration of proteins was $736 \mathrm{mg} \mathrm{g}^{-1}$ dry weight.

$S-A g-\mathrm{S}-\mathrm{Ag}$ were also prepared from protoscoleces obtained by aseptic puncture from fertile hydatid cysts of ovine origin, washed with phosphate-buffered saline (PBS) and stored at $-25^{\circ} \mathrm{C}$ with proteolytic enzyme inhibitors (2 $\mathrm{mM}$ PMSF and $5 \mathrm{mM}$ EDTA). Protoscoleces were thawed and sonicated ( 10 cycles of $12 \mathrm{~s}$ at $60 \mathrm{~Hz}$ frequency), freezethawed once more and centrifuged for $35 \mathrm{~min}$ at $2300 \times \mathrm{g}$. Supernatants were aliquotted and stored at $-25^{\circ} \mathrm{C}$. To perform this study a batch of protoscoleces from a single sheep liver infected with multiple hydatid cysts was selected. Protoscoleces had a viability of $97.4 \%$ at the time of their extraction from the cyst. The concentration of proteins was $2.95 \mathrm{mg} \mathrm{ml}^{-1}$.

$E S-A g$ - To obtain ES-Ag, a total of 10 cultures of protoscoleces from sheep liver were carried out. Initial viability was assessed by morphological appearance, flame cell motility and general contractile movements (Howell 1986). Protoscoleces were cultured in PBS complemented with $10 \%$ glucose, $100 \mathrm{U} \mathrm{ml}^{-1}$ penicillin and $100 \mu \mathrm{g}$ $\mathrm{ml}^{-1}$ streptomycin at $37^{\circ} \mathrm{C}$ in $5 \% \mathrm{CO}_{2}$ (Carmena et al. 2002). The medium was renewed every $8 \mathrm{~h}$ and, after $50 \mathrm{~h}$ of culture, concentrated using filters with a $5 \mathrm{kDa}$ pore diameter membrane (Ultrafree 15, Millipore). EDTA $(5 \mathrm{mM})$ and PMSF $(2 \mathrm{mM})$ were added, and the ES products were aliquotted and stored at $-25^{\circ} \mathrm{C}$. To perform this study, a batch of protoscoleces with an initial viability of $95.2 \%$ was obtained from a single liver infected with multiple cysts. The concentration of protein was $0.2 \mathrm{mg} \mathrm{ml}^{-1}$.

Human sera - Thirty two pre- and post-surgery sera from 11 individuals with confirmed liver hydatidosis were assayed by ELISA (HCF as solid phase) for levels of $E$. granulosus specific antibodies. Sera from the five patients with the highest absorbance values in ELISA assays were pooled and used as positive control in the inhibition assays.

Dog sera - Dog sera were collected from the Council Animal Rescue Mission, Vitoria, Spain. Five sera from dogs naturally infected with E. granulosus were obtained. All animals were diagnosed by autopsy. Sera from the four infected dogs with the highest absorbance values in ELISA assays using S-Ag as solid phase (Benito et al. 2001) were pooled and used as positive control in the inhibition assays.

Hyperimmune rabbit sera - Polyclonal immunosera anti-HCF, anti-S-Ag, and anti-ES-Ag were obtained according to Gallart et al. (1985). Titration of rabbit antisera was performed by ELISA, using their homologous antigenic extracts as solid phase.

ELISA-inhibition assays - ELISA was carried out as described by Martínez et al. (1985). Briefly, polystyrene 96-well microtitre plates (Maxisorp ${ }^{\mathrm{TM}}$, Nunc, Roskilde, Denmark) were coated with $100 \mu 1 /$ well of the optimal antigen concentrations determined according to Muñoz et al. (1986) (HCF: $10.5 \mu \mathrm{g} \mathrm{ml}^{-1}$; S-Ag: $7.5 \mu \mathrm{g} \mathrm{ml}^{-1}$; ES-Ag: 20 $\left.\mu \mathrm{g} \mathrm{ml}^{-1}\right)$ diluted in PBS buffer and incubated for $3 \mathrm{~h}$ at room temperature (human ELISA) or $15 \mathrm{~h}$ at $4^{\circ} \mathrm{C}$ (canine ELISA). After blocking with $1 \%$ BSA- $0.05 \%$ Tween 20 in PBS, wells were filled with $50 \mu 1 /$ well of each inhibitory antigenic extract in PBS (serial dilutions ranging from: HCF: 3 to $0 \mathrm{mg} \mathrm{ml}^{-1}$; S-Ag: 1.6 to $0 \mathrm{mg} \mathrm{ml}^{-1}$; ES-Ag: 0.2 to 0 $\mathrm{mg} \mathrm{ml}^{-1}$ ). Fifty $\mu \mathrm{l} /$ well of the tested pooled sera were added at dilutions that had previously been optimized and incubated for $3 \mathrm{~h}$ at $37^{\circ} \mathrm{C}$. Dilutions of the first antibodies were 1:800 for pooled sera from hydatid patients and 1:50 for pooled sera from dogs with E. granulosus infections. Wells were then incubated with peroxidase-conjugated rabbit anti-human $\operatorname{IgG}$ (Dako, 1:2500 dilution) or anti-dog IgG (Sigma, 1:1000 dilution) in 0.05\% Tween 20-PBS for $15 \mathrm{~h}$ at $4^{\circ} \mathrm{C}$. After washing, plates were developed with MBTH-DMAB solution at room temperature for $20 \mathrm{~min}$. The reaction was stopped with $50 \mu \mathrm{l} /$ well of $2 \mathrm{~N} \mathrm{H}_{2} \mathrm{SO}_{4}$ and the OD was measured at $620 \mathrm{~nm}$. Assays were performed in triplicates. OD values from tested sera versus inhibitor concentrations were graphically depicted and percentages of inhibition were calculated with the following formula:

$$
\% \text { inhibition }_{[\mathrm{x}]}=100-\left(\mathrm{OD}_{[\mathrm{x}]} / \mathrm{OD}_{\text {max. }} \times 100\right)
$$

where $\mathrm{OD}_{[\mathrm{x}]}$ is the absorbance value corresponding to the assayed inhibitor concentration, and $\mathrm{OD}_{\text {max. }}$ is the absorbance value corresponding to an inhibitor concentration equal to zero. In addition, values of $\mathrm{Ag}_{50}$ (antigen concentration required to inhibit $50 \%$ of the specific sera antibodies assayed), coefficient of linear correlation, slope of the regression line, and theoretical maximum percentage of inhibition were also calculated for each inhibition reaction (Martínez et al. 1985).

Immunoblotting and immunoblot-inhibition assays Proteins from HCF, S-Ag, and ES-Ag were fractionated by $12.5 \%$ SDS-PAGE under reducing conditions according to Laemmli (1970) and transferred to polyvinylidene difluoride (PVDF) membranes (Immobilon-P, Millipore), according to Towbin et al. (1979). After washing and blocking, membranes were incubated with the sera in $20 \mathrm{mM}$ Tris-buffered saline ( $\mathrm{pH}$ 7.4), 8\% skimmed milk (TBS-M) for $15 \mathrm{~h}$ at $4^{\circ} \mathrm{C}$. Optimal sera dilutions used were: rabbit anti-HCF: 1:1000; rabbit anti-S-Ag: 1:1000; rabbit anti-ESAg: 1:500; pooled sera from hydatid patients: 1:800; pooled sera from dogs with E. granulosus infections: 1:100. Peroxidase-conjugated swine anti-rabbit total Ig (Dako, Copenhagen, Denmark), rabbit anti-human IgG (Dako) and rabbit anti-dog $\operatorname{IgG}$ (Sigma) were used at 1:1000 dilution in TBS-M buffer for $4 \mathrm{~h}$ at room temperature. Membranes were revealed by adding 4-chloro-1-napthol solution. The immunoblotting inhibition assays were performed according to Asturias et al. (1999). Sera used in these assays were previously preabsorbed with each inhibitory antigenic extract (HCF and S-Ag: $1 \mathrm{mg} \mathrm{ml}^{-1}$; ES-Ag: $0.2 \mathrm{mg}$ $\mathrm{ml}^{-1}$ ) for 30 min at $37^{\circ} \mathrm{C}$ with gentle shaking, and then added to the membranes as described before. Non-inhibited sera were used as positive control. Sera that were inhibited with the same extract utilized as solid phase were used as negative control. Resulting antigenic band pat- 
terns were analyzed and apparent molecular masses were estimated by meassuring the relative mobility of each band of interest, and interpolating the data in the standard curve. Proteins which were identified by at least four of the five inhibited antisera assayed (considering each immunoserum used in the inhibition reaction independently) were regarded as overall shared components.

\section{RESULTS}

ELISA-inhibition assays - Table I summarizes the ELISA-inhibition results obtained for the pooled serum from hydatid patients and for the pooled serum from dogs infected with $E$. granulosus both of them being inhibited with the antigenic extracts HCF, S-Ag, and ES-Ag. Values corresponding to correlation coefficients (r), slopes of the regression lines, $\mathrm{Ag}_{50}$, and theoretical maximum percentages of inhibition are shown. According to the analysis of these data, high cross-reactivity was mainly observed for S-Ag and ES-Ag. Furthermore, the pool of dog sera showed considerably higher $\mathrm{Ag}_{50}$ values than the pool of human sera, when assayed under the same conditions.

Immunoblotting and immunoblot-inhibition assays Fig. 1 shows the antigenic profiles of HCF, S-Ag, and ESAg when using the different non-inhibited and inhibited immunosera. For better comprehension, the patterns of the protein bands are also presented in a schematic figure. Thirteen polypeptides ranging from 9 to $108 \mathrm{kDa}$ were identified in the HCF when the non-inhibited rabbit serum against HCF was used (Fig. 1-A). Antigens of 108 and 78 $\mathrm{kDa}$ were specific for HCF (rabbit antibodies against these polypeptides did not bind to any S-Ag or ES-Ag components). The non-inhibited rabbit antiserum against $\mathrm{S}-\mathrm{Ag}$ recognized 13 antigenic components ranging from 6 to
$124 \mathrm{kDa}$ when S-Ag was used as solid phase. Polypeptides of $124,94,83$, and $75 \mathrm{kDa}$ were found to be specific for this antigenic extract (Fig. 1-B). Finally, the non-inhibited rabbit serum against ES-Ag reacted specifically with at least 14 components from the ES-Ag, some of which $(89,66,42,40,37$, and $35 \mathrm{kDa})$ are neither shared by S-Ag nor by $\mathrm{HCF}$ (Fig. 1-C). In addition, immunoblot-assays were carried out using each rabbit antiserum against its heterologous antigenic extracts as solid phase.

Table II summarizes the molecular masses of the major antigenic proteins shared by HCF, S-Ag, and ES-Ag, considering each immunoserum used in the inhibition reaction independently. The antigenic components identified as shared components had apparent molecular masses of 4-6, 20-24, 52, 80, and 100-104 kDa, including doublets of $41 / 45,54 / 57$, and 65/68 kDa.

\section{DISCUSSION}

Cyst hydatid fluid and somatic antigens of protoscoleces are the best characterized antigenic extracts of E. granulosus, and the main antigenic sources used for immunodiagnosis of human and dog echinococcosis (Rickard \& Lightowlers 1986, Lightowlers \& Gottstein 1995). During recent years, ES-Ag have acquired a role in the diagnosis of infections in the definitive host, based on the detection of these antigens in faeces by ELISA (Fraser \& Craig 1997, Jenkins et al. 2000, Benito \& Carmena 2005). So far, little information is available in regard to the description of ES-Ag. We have recently carried out the biochemical characterization of this antigenic extract, evaluating its potential for immunodiagnosis of human cystic echinococcosis and dog echinococcosis (Carmena et al. 2004, 2005). However, until now no studies have been performed to determine the homology degree among

TABLE I

Results of the ELISA-inhibition assays for the pool of human sera from individuals with confirmed hydatidosis and for the pool of sera from dogs naturally infected with Echinoccus granulosus

\begin{tabular}{|c|c|c|c|c|c|c|}
\hline Sera & $\begin{array}{l}\text { Solid } \\
\text { phase }\end{array}$ & $\begin{array}{l}\text { Inhibitor } \\
\text { extract }\end{array}$ & $\mathrm{r}$ & Slope & $\begin{array}{c}\mathrm{Ag}_{50} \\
(\mathrm{mg} / \mathrm{ml})\end{array}$ & $\begin{array}{c}\text { Theoretical \% } \\
\text { inhibition }\end{array}$ \\
\hline \multirow[t]{9}{*}{ Pooled human serum } & \multirow[t]{3}{*}{$\mathrm{HCF}$} & $\mathrm{HCF}$ & 0.9822 & 11.8 & 0.106 & 100 \\
\hline & & S-Ag & 0.9848 & 16.0 & 0.416 & 85.6 \\
\hline & & ES-Ag & NA & NA & NA & NA \\
\hline & \multirow[t]{3}{*}{ S-Ag } & $\mathrm{HCF}$ & 0.9817 & 12.4 & 0.420 & 65.2 \\
\hline & & S-Ag & 0.9900 & 11.7 & 0.051 & 100 \\
\hline & & ES-Ag & 0.9948 & 14.2 & 0.123 & 92.6 \\
\hline & \multirow[t]{3}{*}{ ES-Ag } & $\mathrm{HCF}$ & 0.9920 & 7.5 & 1.247 & 45.8 \\
\hline & & S-Ag & 0.9720 & 7.9 & 0.119 & 72.5 \\
\hline & & ES-Ag & 0.9857 & 13.1 & 0.060 & 100 \\
\hline \multirow[t]{9}{*}{ Pooled dog serum } & \multirow[t]{3}{*}{$\mathrm{HCF}$} & $\mathrm{HCF}$ & 0.9891 & 9.9 & 0.119 & 100 \\
\hline & & S-Ag & 0.9913 & 13.4 & 0.572 & 87.1 \\
\hline & & ES-Ag & 0.9538 & 9.9 & 0.676 & 74.6 \\
\hline & \multirow[t]{3}{*}{ S-Ag } & $\mathrm{HCF}$ & 0.9919 & 5.6 & 3.459 & 59.3 \\
\hline & & S-Ag & 0.9987 & 10.0 & 0.354 & 100 \\
\hline & & ES-Ag & 0.9723 & 6.8 & 0.931 & 74.2 \\
\hline & \multirow[t]{3}{*}{ ES-Ag } & $\mathrm{HCF}$ & 0.9860 & 6.7 & 1.104 & 100 \\
\hline & & S-Ag & 0.9951 & 5.8 & 3.715 & 99.8 \\
\hline & & ES-Ag & 0.9951 & 4.9 & 1.349 & 100 \\
\hline
\end{tabular}

HCF: hydatid cyst fluid; S-Ag: somatic antigens; ES-Ag: excretory-secretory antigens; NA: not available 


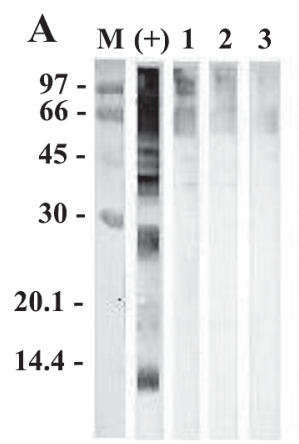

Rabbit anti-HCF

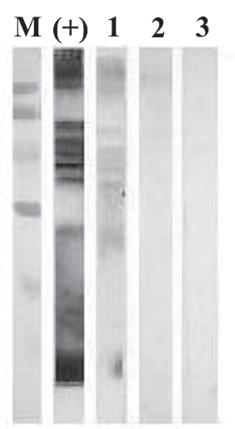

Pool human sera
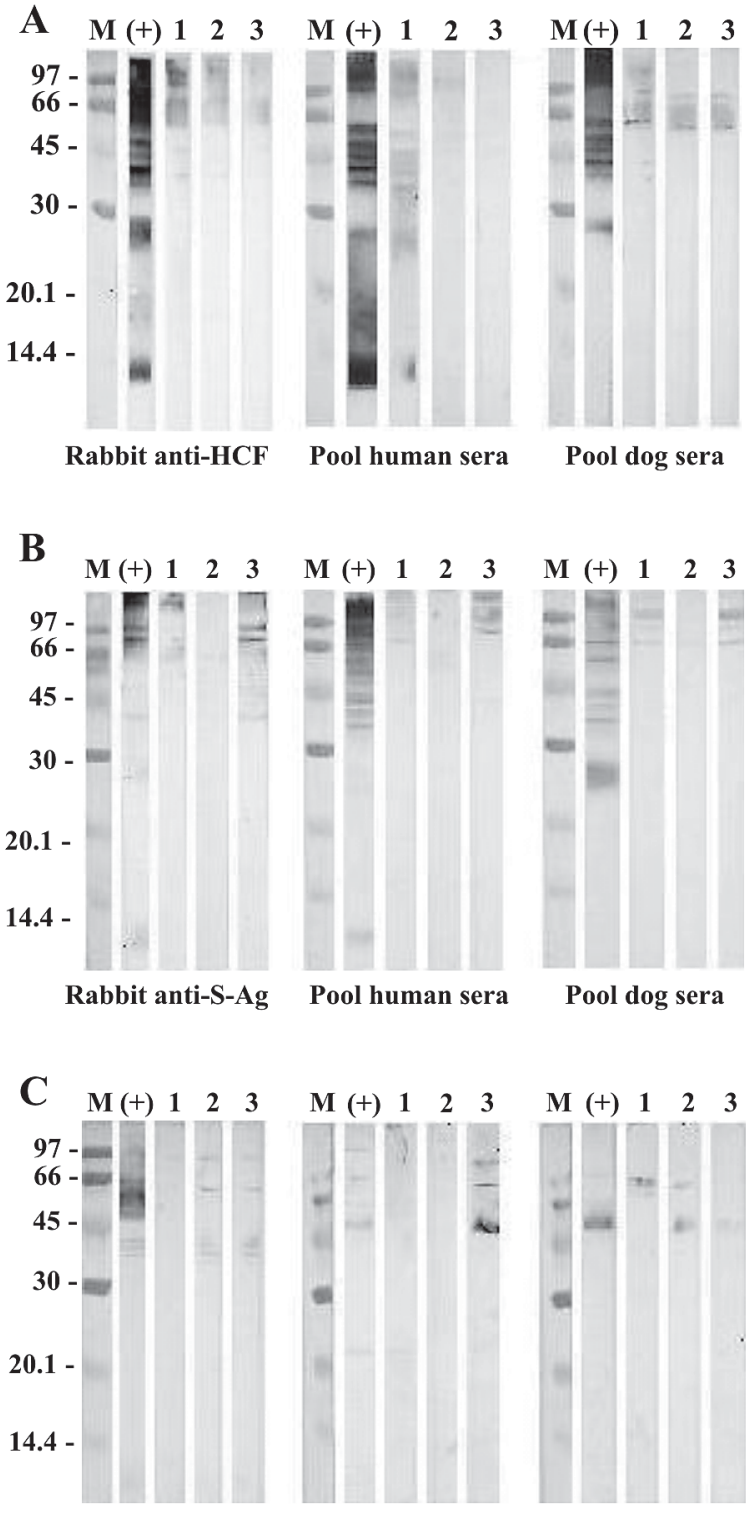

Rabbit anti-ES-Ag Pool human sera
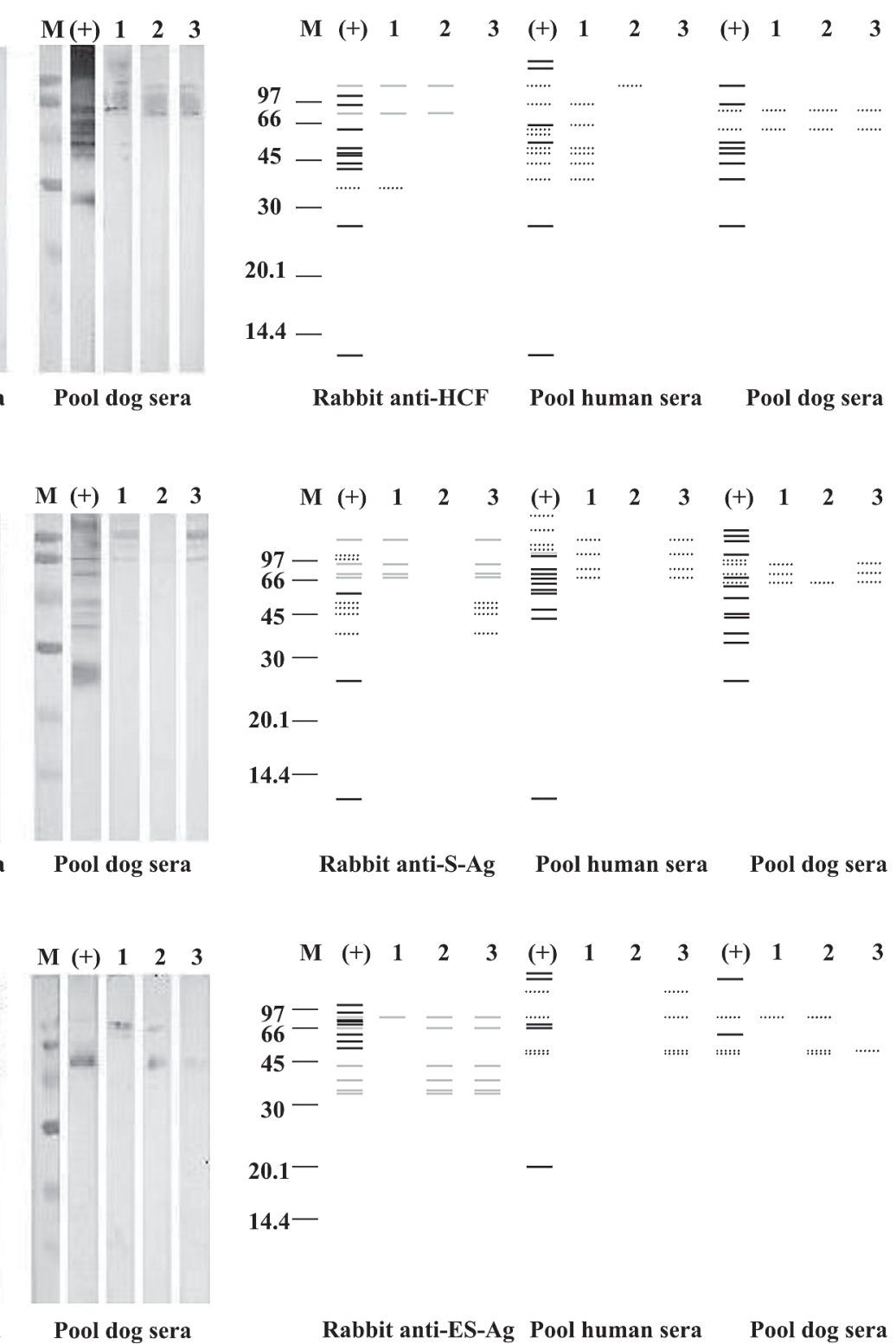

Rabbit anti-ES-Ag Pool human sera Pool dog sera

Fig. 1: immunoblotting profiles and schematic figures of the protein bands obtained when using inhibited and non-inhibited immunosera. A: hydatid cyst fluid (HCF); B: somatic antigens (S-Ag); C: excretory-secretory antigens (ES-Ag); M: molecular mass marker, expressed in $\mathrm{kDa}$; (+): non-inhibited serum; 1: inhibited serum with ES-Ag; 2: inhibited serum with S-Ag; 3: inhibited serum with HCF. Non-shared components are indicated as grey bands. Shared components are indicated as black bands.

the antigenic components of HCF, S-Ag, and ES-Ag, and to find out their non-shared and shared proteins.

ELISA-inhibition results using both the pool of human sera from individuals with confirmed hydatidosis and the pool of sera from dogs infected with E. granulosus have shown a great resemblance with regard to the slopes of the regression lines corresponding to each antigenic extract used as solid phase. This fact indicates that there are antigens shared by HCF, S-Ag, and ES-Ag. The highest cross-reactivity was observed between S-Ag and ES$\mathrm{Ag}$. These results are supported by $\mathrm{Ag}_{50}$ values, since inhibition of $50 \%$ of the specific serum antibodies in each inhibition reaction test required higher concentrations of $\mathrm{HCF}$ antigens than of S-Ag and ES-Ag. Interestingly, the pool of dog sera showed considerably higher $\mathrm{Ag}_{50}$ values than the pool of human sera, when assayed under the same conditions. These results demonstrate that dog antibodies have a lower avidity for their specific antigens than antibodies of human origin. This phenomenon may be explained by the concept of antibody affinity maturation through the course of species evolution. It is known that less evolved species have antibodies with lower affinity for their specific epitopes than higher evolved species (Du Pasquier 2001, Frank 2002). We consider that this 
TABLE II

Major antigenic components shared by hydatid cyst fluid (HCF), protoscoleces somatic antigens (S-Ag), and excretory-secretory antigens (ES-Ag) recognized by the different used antisera by immunoblotting and blotting-inhibition. Molecular masses are expressed in $\mathrm{kDa}$

\begin{tabular}{|c|c|c|c|c|}
\hline \multicolumn{3}{|c|}{ Rabbit sera } & \multirow[b]{2}{*}{ Pool of human sera } & \multirow[b]{2}{*}{ Pool of dog sera } \\
\hline Anti-HCF & Anti-S-Ag & Anti-ES-Ag & & \\
\hline- & - & - & $133-135$ & $130-133$ \\
\hline 117 & 113 & - & - & 115/122(D) \\
\hline & - & 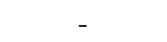 & - & $104-110$ \\
\hline 100 & $99-100$ & $100-104$ & - & - \\
\hline- & - & 93/99(D) & - & 97 \\
\hline 89-91 & 91 & - & - & - \\
\hline 84 & 86 & $86-88$ & - & - \\
\hline 79 & 80 & 80/83(D) & 81 & - \\
\hline - & - & $76-77$ & - & 76 \\
\hline - & - & $70-71$ & - & - \\
\hline - & $65-69$ & 67 & 65/68(D) & - \\
\hline 62-65(D) & - & $63-65$ & - & $62-64$ \\
\hline- & - & - & $59-60$ & - \\
\hline - & 57/62(D) & 57 & 56 & $56-57$ \\
\hline $54 / 57(D)$ & 55 & - & - & 54 \\
\hline 52 & 52 & 52 & 52 & - \\
\hline 49 & - & - & 49 & 48 \\
\hline 41/45(D) & 44/46(D) & 41/45(D) & 41/44(D) & 41/43(D) \\
\hline & 37 & - & 38 & $38-39$ \\
\hline- & - & - & 34 & 34 \\
\hline - & 32 & 30 & - & - \\
\hline 23 & $21-23$ & 24 & $20-23$ & $21-22$ \\
\hline
\end{tabular}

D: doublet

may be one of the several reasons why a lower sensitivity was observed in assays for the serodiagnosis of dog echinococcosis as compared to assays for the immunodiagnosis of human cystic echinococcosis.

Immunoblotting and immunoblot-inhibition assays were carried out in order to describe the profiles of the non-shared and shared antigenic components among the different extracts of E. granulosus studied: HCF, S-Ag, and ES-Ag. Each antigenic extract was assayed against its homologous and heterologous rabbit antisera, the pool of human sera from individuals with confirmed hydatidosis and the pooled sera from dogs infected with $E$. granulosus, with and without inhibition. It is necessary take into consideration that the reported molecular mass estimations can have slight inaccuracies as a consequence of the limitations of the measurement method used. Among the shared components of the three antigenic extracts, the polypeptide of 4-6 kDa corresponds very likely to the $8 \mathrm{kDa}$ subunit of the $\mathrm{AgB}$. This component is strongly recognized by the non-inhibited pool of sera from patients infected with cystic echinococcosis and the rabbit sera anti-HCF/S-Ag, but not by the non-inhibited pool of sera from dogs infected with E.granulosus (Fig. 1-A, B). This fact confirms that $\mathrm{AgB}$ is present in the metacestode of the parasite, but not in the adult stage. Similarly, the polypeptide of 20-24 kDa may correspond to subunits of $\mathrm{Ag} 5$ or $\mathrm{Ag} \mathrm{B}$, and the component of $41 \mathrm{kDa}$ may match the major subunit of Ag 5 (Lightowlers et al. 1989, Ortona et al. 1995, González et al. 1996). Some of the products identified in $\mathrm{HCF}$ by the pool of human sera in the present study may correspond to those previously described by other authors using the same antigenic extract. This may be the case of the protein of $34 \mathrm{kDa}$ (recently identified by Poretti et al. 1999), and the protein of $110 \mathrm{kDa}$, probably related with the component of $100 \mathrm{kDa}$ described by Shambesh et al. (1995), the protein of 110-120 kDa (Shapiro et al. 1992), and the protein of $116 \mathrm{kDa}$ (Kanwar et al. 1992).

Some of the immunoblot-inhibition assays showed some bands in the negative controls, indicating that the inhibition reaction was not complete. This fact was detected more frequently when ES-Ag were used as inhibitory extract, and may probably be due to a lower concentration of protein used in the inhibition reaction.

Non-shared antigenic components of each extract from E. granulosus (HCF, S-Ag, and ES-Ag) were determined by analysing the profiles obtained by immunoblotting and comparing them with profiles that were obtained when the antisera were inhibited with the different antigenic extracts tested. HCF evidenced two non-shared components of 108 and $78 \mathrm{kDa}$, respectively. S-Ag showed four non-shared polypeptides with apparent molecular masses of $124,94,83$, and $75 \mathrm{kDa}$. On the other hand, ES-Ag showed non-shared antigenic components of 89, 66, 42, 40,37 , and $35 \mathrm{kDa}$. The protein of $89 \mathrm{kDa}$ has already demonstrated specificity for immunodiagnosis of human cystic echinococcosis and dog echinococcosis in previous reports (Carmena et al. 2004, 2005). This component 
may be responsible for the higher specificity shown by ES-Ag in comparison to S-Ag in ELISA assays used for serodiagnosis of dog echinococcosis.

In summary we can conclude that HCF, S-Ag, and ESAg share an important proportion of antigens, which explains the high level of cross-reactivity found in ELISAinhibition and immunoblot-inhibition assays when these extracts were used. The identification of shared and nonshared immunogenic components of HCF, S-Ag, and ESAg may provide information that could prove very useful when searching for specific components or antigens with potential for the immunodiagnosis of human cystic echinococcosis and dog echinococcosis.

\section{ACKNOWLEDGEMENTS}

To Dr Sonja Kock and Dr David Guiliano (Department of Biological Sciences, Imperial College London, UK) for their critical revision of this manuscript.

\section{REFERENCES}

Asturias J, Gómez-Bayón N, Arilla MC, Martínez A, Palacios R, Sánchez-Gascón F, Martínez J 1999. Molecular characterization of american cockroach tropomyosin (Periplaneta americana Allergen 7), a cross-reactive allergen. J Immunol 162: 4342-4348.

Auer H, Hermentin K, Aspöck H 1988. Demonstration of a specific Echinococcus multilocularis antigen in the supernatant of in vitro maintained protoscoleces. Zbl Bakt Mik Hyg 268: 416-423.

Benito A, Carmena D 2005. Double-antibody sandwich ELISA for the detection of Echinococcus granulosus coproantigens in dogs. Acta Trop 95: 9-15.

Benito A, Carmena D, Spinelli P, Postigo I, Martínez J, Estíbalez JJ, Martín de la Cuesta F, Guisantes JA 2001. The serological diagnosis of canine echinococcosis by an enzyme immunoassay useful for epidemiological surveys. Res Rev Parasitol 61: 17-23.

Carmena D, Benito A, Martínez J, Guisantes JA 2005. Preliminary study of the presence of antibodies against excretorysecretory antigens from protoscoleces of Echinococcus granulosus in dogs with intestinal echinococcosis. Mem Inst Oswaldo Cruz, 100: 311-317.

Carmena D, Benito A, Postigo I, Arteaga J, Martínez J, Guisantes JA 2002. Short term culture of protoscoleces to obtain excretory-secretory proteins of Echinococcus granulosus. Res Rev Parasitol 62: 84-88.

Carmena D, Martínez J, Benito A, Guisantes JA 2004. Characterization of excretory-secretory products from protoscoleces of Echinococcus granulosus and evaluation of their potential for immunodiagnosis of human cystic echinococcosis. Parasitology 129: 371-378.

Du Pasquier L 2001. The immune system of invertebrates and vertebrates. Comp Biochem Physiol 129: 1-15.

Frank SA 2002. Hypothetical relations between immunology and phylogeny. In Immunology and Evolution of Infectious Diseases, Princeton University Press, New Jersey, p. 179180.

Fraser A, Craig PS 1997. Detection of gastrointestinal helminth infections using coproantigen and molecular diagnostic approaches. J Helminthol 71: 103-107.
Gallart MT, Blade J, Martínez J, Sierra J, Rozman C, Vives J 1985. Multiple myeloma with monoclonal IgG and IgD of Lambda type exhibiting under treatment, a shift from mainly IgG to mainly IgD. Immunology 55: 45-47.

Gasser RB, Jenkins DJ, Heath DD, Lawrence SB 1992. Use of Echinococcus granulosus worm antigens for immunodiagnosis of Echinococcus granulosus infection in dogs. Vet Parasitol 45: 89-100.

Gasser RB, Lightowlers MW, Obendorf DL, Jenkins DJ, Rickard MD 1988. Evaluation of a serological test system for the diagnosis of natural Echinococcus granulosus infection in dogs using E. granulosus protoscolex and oncosphere antigens. Australian Vet J 65: 369-373.

Gasser RB, Parada L, Acuna A, Burges C, Laurenson MK, Gulland FMD, Reichel MP, Paolillo E 1994. Immunological assesment of exposure to Echinococcus granulosus in a rural dog population in Uruguay. Acta Trop 58: 179-185.

González G, Nieto A, Fernández C, Örn A, Wernstedt C, Hellman $\mathrm{U}$ 1996. Two different $8 \mathrm{kDa}$ monomers are involved in the oligomeric organization of the native Echinococcus granulosus antigen B. Parasite Immunol 18: 587-596.

Howell MJ 1986. Cultivation of Echinococcus species in vitro. In RCA Thompson, The Biology of Echinococcus and Hydatid Disease, George Allen \& Unwin, London, p. 143-163.

Jenkins DJ, Fraser A, Bradshaw H, Craig PS 2000. Detection of Echinococcus granulosus coproantigens in Australian canids with natural or experimental infection. J Parasitol 86: 140145.

Jenkins DJ, Gasser RB, Zeyhle E, Romig T, Macpherson CNL 1990. Assessment of a serological test for the detection of Echinococcus granulosus infection in dogs in Kenya. Acta Trop 47: 245-248.

Kanwar JR, Kaushik SP, Sawhney IMS, Kamboj MS, Mehta SK, Vinayak VK 1992. Specific antibodies in serum of patients with hydatidosis recognised by immunoblotting. $J$ Med Microbiol 36: 46-51.

Laemmli UK 1970. Cleavage of structural proteins during the assembly of the head of bacteriophage T4. Nature 227: 680-685.

Lightowlers MW, Gottstein B 1995. Echinococcosis/hydatidosis: antigens, immunological and molecular diagnosis. In RCA Thompson, AJ Lymbery (eds), Echinococcus and Hydatid Disease, CAB International, Oxon, p. 355-410.

Lightowlers MW, Liu D, Haralambous A, Rickard MD 1989. Subunit composition and specificity of the major cyst fluid antigens of Echinococcus granulosus. Mol Biochem Parasitol 37: 171-182.

Martínez J, Nieto A, Vives J, Torres JM 1985. Application of ELISA-inhibition to Aspergillus antigen standardization for immunodiagnosis. J Med Vet Mycol 23: 317-320.

Muñoz C, Nieto A, Gayá A, Martínez J, Vives J 1986. New experimental criteria for optimization of solid-phase antigen concentrations and stability in ELISA. J Immunol Methods 94: 137-144.

Ortona E, Siracusano A, Castro A, Riganò R, Mühlschlegel F, Ioppolo S, Notargiacomo S, Frosch M 1995. Use of a monoclonal antibody against the antigen $\mathrm{B}$ of Echinococcus granulosus for purification and detection of antigen B. Appl Parasitol 36: 220-225. 
Poretti D, Felleisen R, Grimm F, Pfister M, Teuscher F, Zuercher C, Reichen J, Gottstein B 1999. Differential immunodiagnosis between cystic hydatid disease and other cross-reactive pathologies. Am J Trop Med Hyg 60: 193-198.

Rickard MD, Lightowlers MW 1986. Immunodiagnosis of hydatid disease. In RCA Thompson, The Biology of Echinococcus and Hydatid Disease, George Allen \& Unwin, London, p. 217-249.

Romig T 2003. Epidemiology of echinococcosis. Langenbeck Arch Surg 388: 209-217.

Shambesh MK, Craig PS, Gusbi AM, Echtuish EF, Wen H 1995. Immunoblot evaluation of the 100 and $130 \mathrm{kDa}$ antigens in camel hydatid cyst fluid for the serodiagnosis of human cystic echinococcosis in Libya. Tran $R$ Soc Trop Med Hyg 89: 276-279.

Shapiro SZ, Bahr GM, Hira PR 1992. Analysis of host components in hydatid cyst fluid and immunoblot diagnosis of human Echinococcus granulosus infection. Ann Trop Med Parasitol 86: 503-509.

Towbin H, Staehelin T, Gordon J 1979. Electrophoretic transfer of proteins from polyacrylamide gels to nitrocellulose sheets: procedure and some applications. Proc Nat Acad Sci USA 76: 4350-4354.

Varela-Díaz VM, Coltorti EA, Ricardes MI, Guisantes JA, Yarzábal LA 1974. The immunoelectrophoretic characterization of sheep hydatid cyst fluid antigens. Am J Trop Med Hyg 26: 1092-1096.

Verastegui M, Moro P, Guevara A, Rodríguez T, Miranda E, Gilman RH 1992. Enzyme-linked immunoelectrotransfer blot test for diagnosis of human hydatid disease. J Clin Microbiol 30: 1557-1561.

Zhang W, Li J, McManus DP 2003. Concepts in immunology and diagnosis of hydatid disease. Clin Microbiol Rev 16: 18-36. 